\title{
Rapid differentiation among Lactobacillus, Pediococcus and Weissella species from some Nigerian indigenous fermented foods
}

\author{
A.T. Adesulu-Dahunsi ${ }^{\text {a, b, }}{ }^{*}$, A.I. Sanni ${ }^{a}$, K. Jeyaram ${ }^{\text {b }}$ \\ a Department of Microbiology, University of Ibadan, Ibadan, Oyo State, Nigeria \\ ${ }^{\mathrm{b}}$ Microbial Resources Division, Institute of Bioresources and Sustainable Development (IBSD), Imphal 795001, Manipur, India
}

\section{A R T I C L E I N F O}

\section{Article history:}

Received 1 July 2016

Received in revised form

26 August 2016

Accepted 6 November 2016

Available online 9 November 2016

\section{Keywords:}

Lactic acid bacteria

Indigenous foods

Molecular techniques

ARDRA

GRAS

\begin{abstract}
A B S T R A C T
The taxonomic differentiation among lactic acid bacteria (LAB) using only phenotypic methods is inadequate. In the past, several phenotypic techniques have been applied in identification of different species of LAB from Nigerian indigenous fermented foods. In this study, two less-expensive and rapid molecular techniques were employed in the identification and differentiation of LAB species isolated from some Nigerian fermented foods: gari (cassava mash), fufu (cassava dough) and ogi (maize gruel) to avoid the common errors that are synonymous with the use of conventional methods. The size of the amplified products for the LAB species using universal primers fD1 and rD1 was about $1500 \mathrm{bp}$. The differentiation of the three predominant LAB, Lactobacillus plantarum, Pediococcus pentosaceus and Weissella confusa to species level was performed by intergenic transcribed spacer (ITS-PCR) and amplified ribosomal DNA restriction analysis (ARDRA) using three restriction endonucleases: Hinfl, HaeIII and RsaI. In summary, the study demonstrated that the ARDRA and ITS-PCR analysis are simple, fast and efficient methods that can be used for the routine identification and rapid differentiation of LAB species which are often regularly used as probiotics, starter culture and biopreservative in fermented foods consumed since they are generally regarded as safe (GRAS).
\end{abstract}

(c) 2016 Elsevier Ltd. All rights reserved.

\section{Introduction}

Indigenous fermented foods form the bulk of diet for the populace in Nigeria and other nations in Sub-Saharan Africa. Different economic classes ranging from low to middle income earners all depends largely on fermented foods for their daily survival and this has spurred the cultivation and production of such foods to be on the increase. Lactic acid bacteria (LAB) are known to perform essential roles during the fermentation of these foods (Tamang, 2010), they are beneficial microorganisms, which are commonly isolated from various fermented food products globally (LeBlanc et al., 2013; Tamang et al., 2012). They are largely involved in the fermentation of many Nigerian indigenous fermented foods such as cassava (to produce gari and fufu), maize and sorghum (to produce ogi) (Banwo, Abiodun, Tan, \& Tian, 2012;Oguntoyinbo \& Narbad, 2012; Sanni, Morlon-Guyot, \& Guyot, 2002). The identification of these LAB has previously been based on traditional

\footnotetext{
* Corresponding author. Department of Microbiology, University of Ibadan, Ibadan, Oyo State, Nigeria.

E-mail address: adesuluchemmy@yahoo.com (A.T. Adesulu-Dahunsi).
}

methods which at times do not allow LAB to be differentiated to species and strain level, thus not being able to detect the phylogenetic relationships among the genus. Most time, the usage of these methods lead to non-reproducibility of the experiments, misidentifications and difficulties in the interpretation of the results, because LAB varies as a result of changes in the conditions of growth, environmental conditions or spontaneous mutations due to the differences in gene expression (Collado, Moreno, Cobo, \& Hernandez, 2006; Mohammed et al., 2009).

Moreover, methods that are universally appropriate for LAB and such that has high resolving power both at the species and intraspecies level would serves as important and valuable tools in their identification (Gevers, Huys, \& Swings, 2001; Mohammed et al., 2009). The use of molecular techniques by many researchers has remained useful for proper identification of these bacteria. These methods are equally reliable and consistent for their proper identification thus helps to select suitable bacterial strains with interesting functional characteristics for biotechnological and industrial applications (Stiles \& Holzapfel, 1997).

At present, several molecular based methods such as sequencing of $16 \mathrm{~S}$ and $23 \mathrm{~S}$ rRNA genes, ribotyping, amplified ribosomal DNA 
restriction analysis (ARDRA), randomly amplified polymorphic DNA (RAPD-PCR), intergenic transcribed spacer (ITS-PCR), pulsed-field gel electrophoresis (PFGE), and amplified fragment length polymorphism (AFLP) have been developed and employed to identify LAB (Doulgeraki, Paramithiotis, Kagkli, \& Nychas, 2010; Fusco, Quero, Stea, Morea, \& Visconti, 2011; Jeyaram, Romi, Singh, Devi, \& Devi, 2010; Munoz-Atienza et al., 2016). Among these methods, amplified ribosomal DNA restriction analysis has been described as a reliable molecular technique for distinctly discriminating closely related species of Bacillus (Adewumi, Oguntoyinbo, Wahengbam, Singh, \& Jeyaram, 2014). Also, the 16 S and 23 S rDNA intergenic transcribed spacer typing method varies in length and sequence from one species to another thereby providing greater genetic variation (Tilsala-Timisjarvi \& Alatossava, 1997). During the classification of LAB genus into species and strain level, sequencing of the $16 \mathrm{~S}$ rDNA gene serves as an important tool for their classification. A prompt and rapid identification of LAB with excellent functional characteristics is of utmost importance in food biotechnology. Interestingly, combination of two or more of these techniques has led to species/strains differentiation among LAB and have played significant role in probiotic bacteriology, and their use as starters in traditional fermented foods in Nigeria and sub-Saharan Africa (Banwo et al., 2012; Oguntoyinbo \& Narbad, 2012).

This study therefore aimed at the use of efficient, rapid and simple identification system based on $16 \mathrm{~S}$ amplified ribosomal DNA restriction analysis and 16S-23 rDNA intergenic transcribed spacer analysis for the differentiation of predominant LAB species associated with some Nigerian indigenous fermented foods.

\section{Materials and methods}

\subsection{Samples collection}

Freshly prepared ogi, gari and fufu samples were obtained from the traditional producers in two Southwestern states of Nigeria (Oyo and Osun). The food samples (100-200 g) collected in a container were transported to the laboratory in cooler box for the microbiological analysis.

\subsection{Lactic acid bacteria strains isolation}

Lactic acid bacteria were isolated from collected food samples at different fermentation time $(0,12,24$ and $36 \mathrm{~h})$ in order to determine the predominant LAB species/strains at each fermentation stage and in understanding the succession pattern of the organisms. Ten grams of each food samples were aseptically removed and diluted in $90 \mathrm{ml}$ sterile physiological saline and homogenized. Sequential dilutions of the homogenate were carried out and were plated on Man Rogosa and Sharpe (MRS) agar (Oxoid, UK). Cycloheximide $(0.1 \mathrm{~g} / \mathrm{l})$ was added to the media for the inhibition of yeast growth according to the method of Meroth, Walter, Hertel, Brandt, and Hammes (2003). The plates were incubated at $30^{\circ} \mathrm{C}$ for $48 \mathrm{~h}$ under anaerobic conditions. Colonies displaying different morphologies were picked from the agar plates and were restreaked on MRS agar medium to obtain pure culture.

\subsection{Phenotypic characterisation of lactic acid bacteria}

Gram staining, catalase production, cell morphology and motility were observed under phase contrast microscope (Leitz, Jena, Germany) (Sneath, Mair, Sharpe, \& Holt, 2009). Carbohydrate fermentation pattern was determined using API 50 CHL kits (bioMerieux, France) according to manufacturer's instructions. All experiments were performed in triplicate.

\subsection{Genomic DNA extraction}

Lysozyme-heat lysis method was employed for the genomic DNA extraction (Jeyaram et al., 2011). The DNA obtained was spectrophotometrically quantified at $260 \mathrm{~nm}$ using the NanoDrop ${ }^{\circledR}$ Technologies, (USA) and DNA with purity level of 1.8 and 2.2 absorbance ratio $\left(A_{260} / A_{280}\right)$ was used as template for PCR. The resulting genomic DNA samples were kept at $-20{ }^{\circ} \mathrm{C}$ till further usage.

\subsection{Polymerase chain reaction amplification of 16S-rRNA gene}

The genomic DNA lysate of the LAB isolates were amplified with the universal primers pair (forward (fD1): 5'-AGAGTTTGATCCTGGCTCAG-3') and reverse (rD1) (5'-AAGGAGGTGATCCAGCCGCA-3') (Weisburg, Bams, Peletiar, \& Lane, 1991) under the following conditions: initial denaturation for $10 \mathrm{~min}$ at $94{ }^{\circ} \mathrm{C}$, followed by 35 cycles of $94^{\circ} \mathrm{C}$ for $1 \mathrm{~min}, 65^{\circ} \mathrm{C}$ for $1 \mathrm{~min}$ and $72{ }^{\circ} \mathrm{C}$ for $30 \mathrm{~s}$, and terminated with an elongation step at $72{ }^{\circ} \mathrm{C}$ for $7 \mathrm{~min}$.

\subsection{Amplified ribosomal DNA restriction analysis (ARDRA)}

The restriction digestion of the amplified 16S rRNA gene of about 1500 bp intact were performed separately for each enzyme with Hae III (Sigma), Hinfl (Sigma) and Rsa I (Sigma) according to the method of Jeyaram et al. (2010). The LAB isolates having similar ARDRA profile were grouped together.

\subsection{S-23S rRNA gene intergenic transcribed spacer PCR amplification (ITS-PCR)}

The 16S-23S rRNA (ITS-PCR) amplification was carried out using forward and reverse primers (16SF-R2:5'CGCGGGATCCTTGTACACACCGCCCGTCC-3') and (23SR-R10: $5^{\prime}$ GGCCGTCGACCCTTTCCCTCACGGTACTG-3') (Lechner et al., 1998).

\subsection{Phylogenetic analysis}

The ARDRA and ITS-PCR profiles were processed using NTSYSpc software version 2.20 for generation of cluster analysis in a dendogram based on the Jaccard similarity coefficient $\left(\mathrm{S}_{\mathrm{J}}\right)$ and the unweighed pair group method using arithmetic averages (UPGMA). Duplicate experimental profiles of randomly selected species were performed to evaluate the level of reproducibility.

\subsection{Lactic acid bacteria species identification by $16 S$ rRNA gene sequencing}

The 16S rRNA gene of the representative isolates each from the three identified LAB species was amplified and purified using NucleoSpin ${ }^{\circledR}$ Extract II gel extraction kit (Machery-Nagel, Germany) following manufacturer's instructions. The sequencing services was performed by Merck Specialties Private Limited, Banglore, India, in both directions with the same primers used for the PCR amplification (fD1 and rD1) and an additional forward primer F515 (5'GTGCCAGCCGCCGCGGTAA-3') so as to get maximum reads in an automated ABI 3100 Genetic Analyzer (Applied Biosystems, USA). By analyzing the electrophenogram data using Chromas LITE v2.01 software, the sequence reads were validated. The gene sequences obtained were queried with NCBI GenBank and Ribosomal Database Project (RDP) to identify the closest known relatives, release 10 using BLAST and SEQMATCH algorithms respectively. A neighbor joining method was used to construct the phylogenetic tree using Mega 6.06 (Tamura et al., 2011). 


\subsection{Nucleotide sequence accession number}

The 16S gene sequences of the selected LAB isolates in this study were deposited in GenBank assigned with GenBank accession numbers; L. plantarum GA106, OF101, FU137, YO175, OB123 (KU892392, KU892393, KU892394, KU892395, KU892396), Weissella sp. GA44, OF126, WS90 (KU892397, KU892398, KU892399) and $P$. pentosaceus OF134, OF31, FU20, FU52, YO105, OB55, OB58 (KU892402, KU892403, KU892404, KU892405, KU892406, KU892407, KU892408).

\section{Results and discussion}

A total of ninety four (94) LAB were isolated at the different stages of traditional fermentation of the Nigerian indigenous fermented foods. In all, there were 31 isolates from gari and fufu while the remaining 63 were from ogi. The presumptive identification of LAB using phenotypic methods identified the microorganisms as Gram positive, catalase negative, oxidase negative, and non-motile homofermentative/heterofermentative rods or cocci. They were predominantly genus Lactobacillus (51\%), Pediococcus (32\%) and Weissella (17\%). This report conform to the previous studies on the diversity and microbiological composition of LAB isolated from ogi and fermented cassava mash for production of fufu and gari (Kostinek et al., 2005; Odunfa \& Adeyele, 1985). Teniola, Odunfa, and Holzapfel (2005) reported that Lactobacillus species are the predominant microorganisms during the fermentation of ogi-baba and were also reported to have therapeutic importance to human. Studies of some indigenous fermented foods products in Nigeria have shown that LAB are beneficial microorganisms that are found in foods as they play significant roles such as increasing the efficiency of immune system, enhancing food assimilation, prevention of diseases/ailments predominantly among infants. Banwo et al. (2012) also confirmed that Lactobacillus and Pediococcus species were involved in the early stages of the fermentation of ogi.

The genotypic diversity among the LAB species was determined using polyphasic approach, sequencing and analysis of the $16 \mathrm{~S}$ and 23S rRNA genes are considered as one of the basis of modern microbial taxonomy. The $\mathrm{LAB}$ isolates were subjected to genotypic identification using PCR techniques. The 16S rRNA gene using LAB universal primers fD1 and rD1 gave good amplification for all the isolates. The PCR products contained approximately $1500 \mathrm{bp}$ and corresponded to the expected size of the 16S rRNA genes on the nucleotide sequence data. The isolates with their reference strains were taxonomically identified by ARDRA based grouping using three different restriction endonuclease enzymes HaeIII, Hinfl and RsaI. From the digestion profile of the three restriction endonucleases, restriction digested products of HaeIII distinctly differentiated the representative $\mathrm{LAB}$ isolates into three species as shown in the dendrogram (Fig. 1), where three different band patterns were obtained but the two other restriction endonucleases; Hinfl and Rsal could not distinctly differentiates into species as they possess similar polymorphisms. Based on the differences in the HaeIII digestion profile, three genotypic groups were obtained (phylotypes I-III), Lactobacillus plantarum species showed four bands (molecular weights 150, 350, 480 and 600 bp), Pediococcus pentosaceus species with four bands (molecular weights 150, 310, 450 and $590 \mathrm{bp}$ ), and in Weissella confusa species having two bands with (molecular weights 350 and 1300 bp). The ARDRA technique allowed for the discrimination among these three related genus with the use of only one restriction enzyme HaelII, since distinctive profiles were obtained for each species. From this result, it is evident that ARDRA can be used successfully for the LAB differentiation into species levels when suitable restriction endonuclease(s) are used. This is in agreement with other investigators who

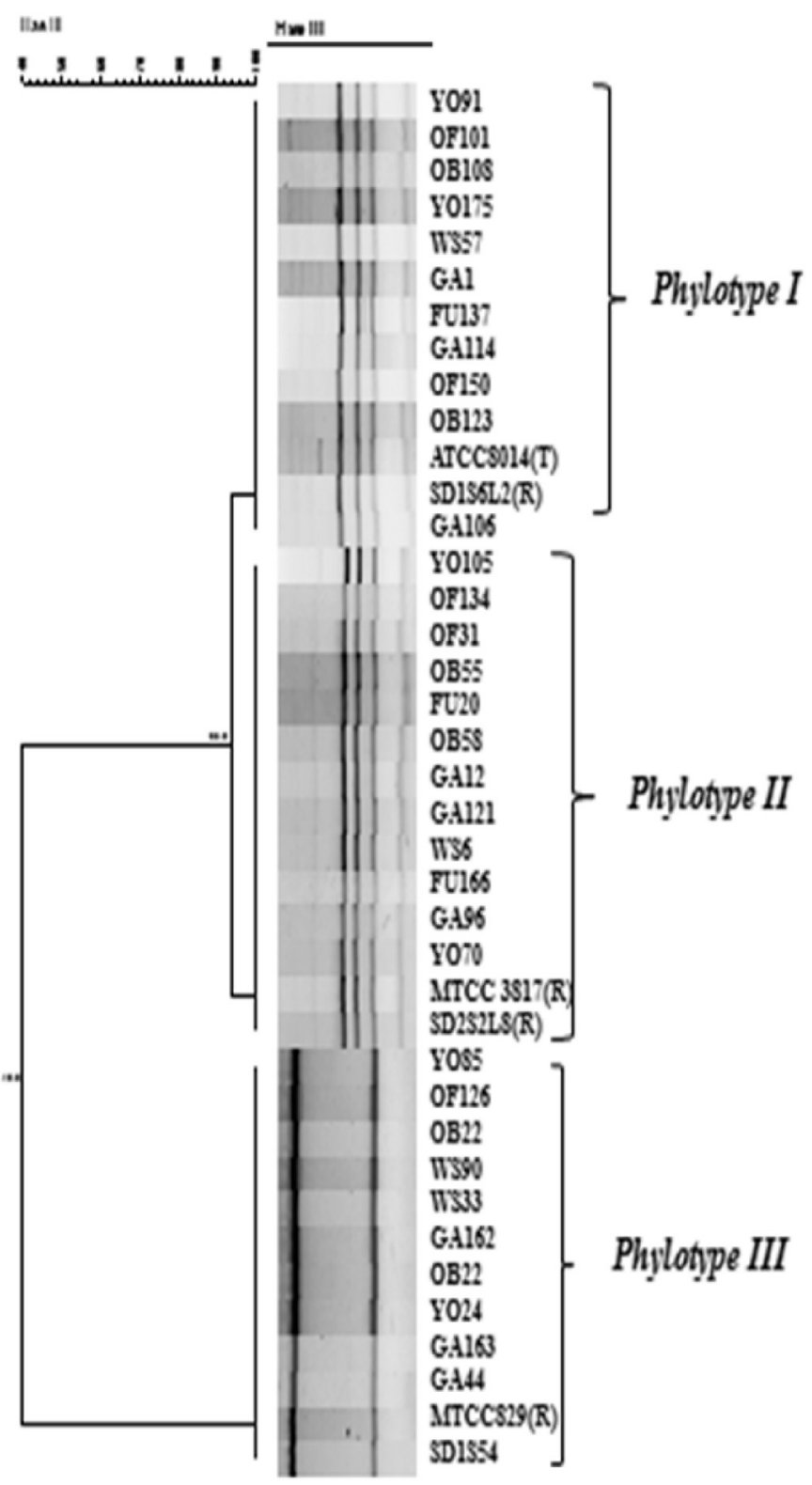

Fig. 1. Dendogram based on the UPGMA clustering with Dice coefficient of HaeII ARDRA pattern.

differentiated three related genus of LAB species from fermented milk products using only one restriction enzyme $M w o I$ and showed distinctive profile for each genus (Collado \& Hernandez, 2007). Oguntoyinbo et al. (2010) successfully differentiated closely related species of Bacillus isolated from Nigerian traditional fermented condiments using ARDRA. Other researchers have also reported the use of $16 \mathrm{~S}$ and $23 \mathrm{~S}$ rRNA sequence for the identification and differentiation of Lactobacilli (Changnaud, Machinis, Coutte, Marecat, \& Merceiner, 2001; Escalante, Wacher, \& Farres, 2001; Versalovic, Schnedier, De Bruijn, \& Lupski, 1994).

Moreso, a considerable variation can occur among species both at the length and sequence of 16S rDNA ITS region. Therefore, ITS region is useful in characterization of bacteria species (Mohammed, Magray, Kumar, Rawat, \& Srivastavs, 2011). Amplification of the 16S-23S rDNA intergenic transcribed spacer PCR could also differentiate the representative isolates into three major species (Fig. $2 a-c)$. Other researchers have used the amplification size 
a)

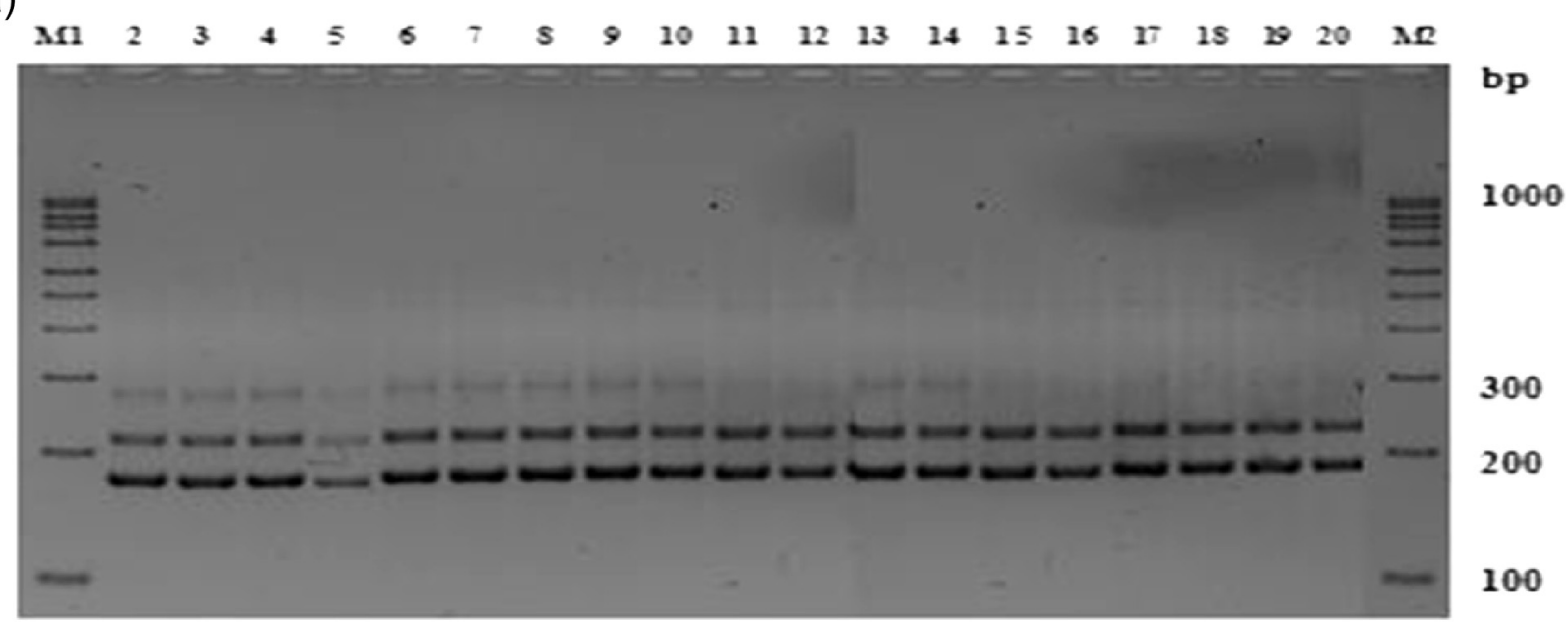

b)

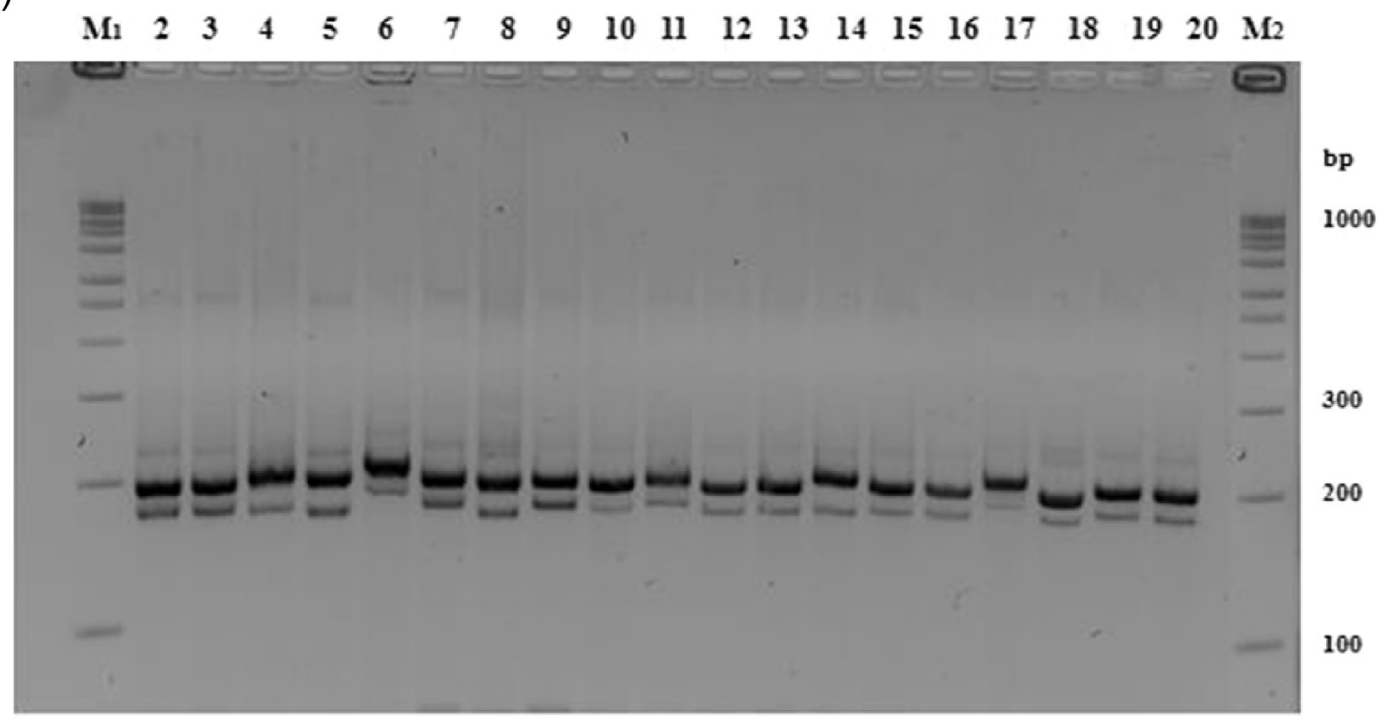

c)

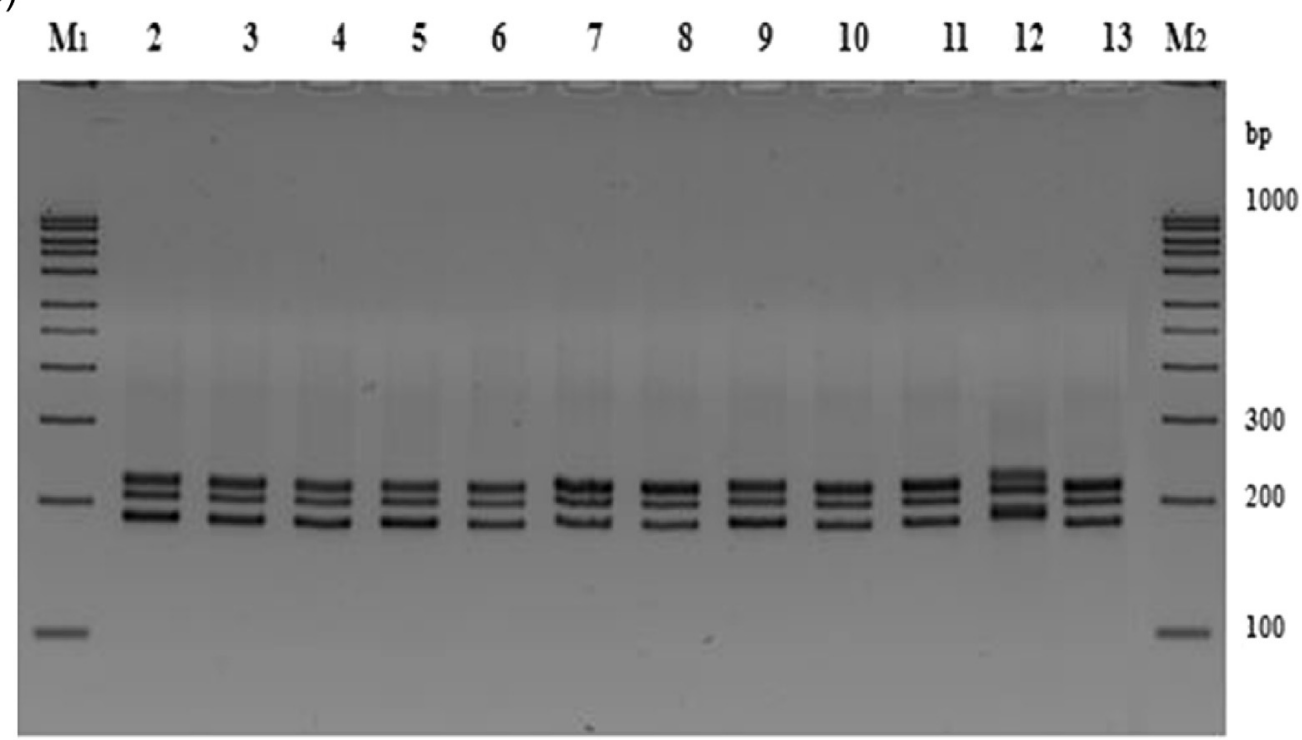

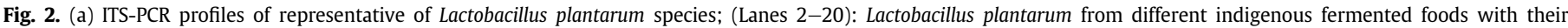

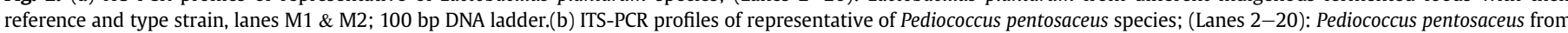

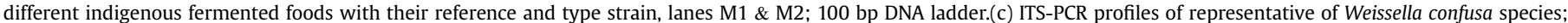
(Lanes 2-13): Weissella species from different indigenous fermented foods with their reference and type strain, lanes M1 \& M2; 100 bp DNA ladder. 


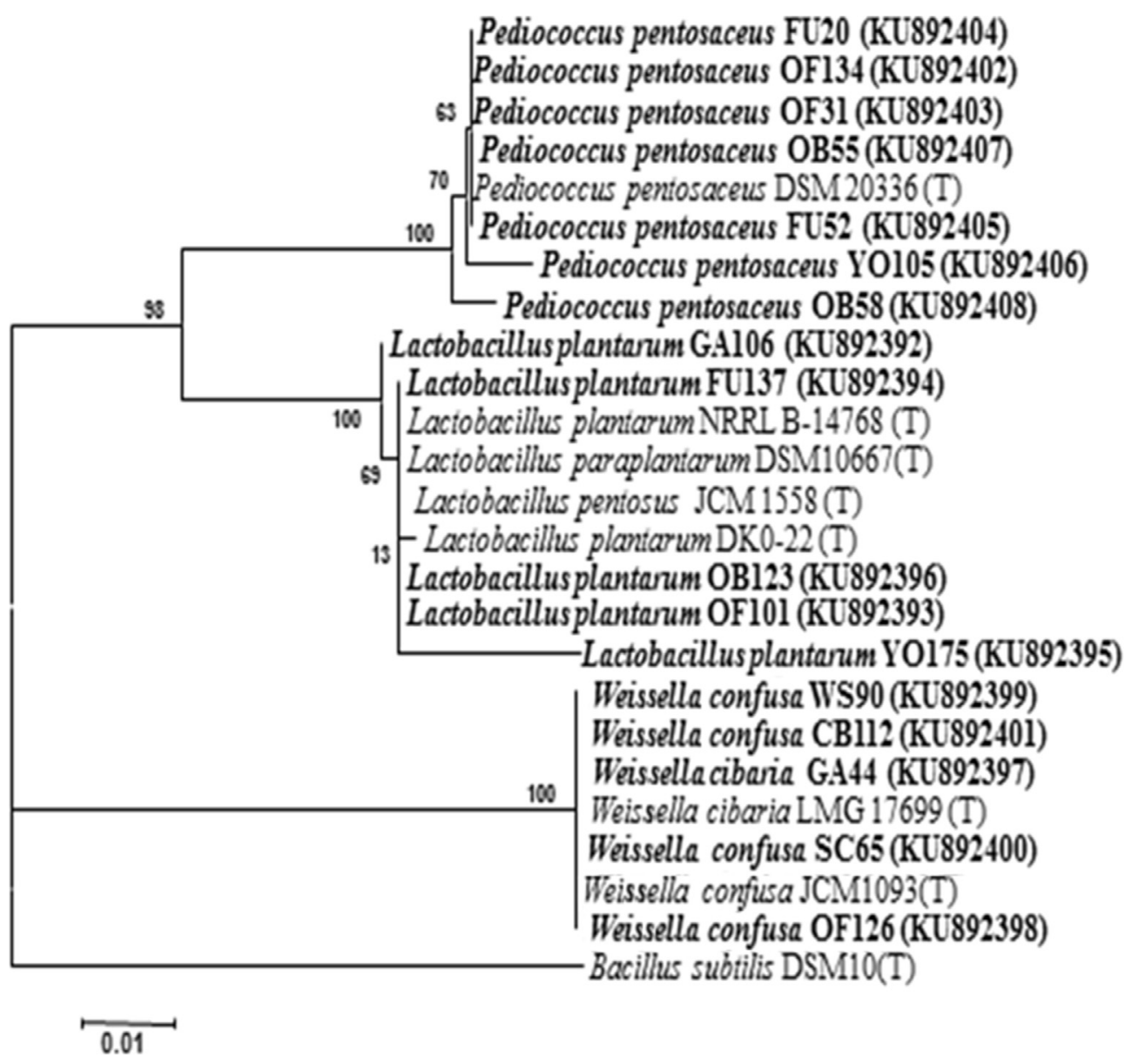

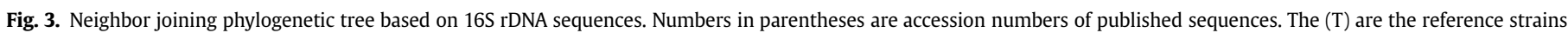
from NCBI and Bacillus subtilis is the out group used for tree construction.

polymorphisms of ITS for the identification of bacteria at species level (Cho \& Tiedje, 2000; Jensen, Webster, \& Strauss, 1993). Polymerase chain reaction amplification of the 16S-23S rRNA gene internal transcribed spacer (ITS-PCR) maintained the interspecies differentiation generated by ARDRA. The length variation in ITS region is mainly due to the type and number of tRNA genes interspersed (Osorio, Collins, Romalde, \& Toranzo, 2005) and the difference in intensities of band is due to the number of rRna operons present (Moreira et al., 2005).

The result obtained from the 16S rDNA gene sequencing of the LAB strains in this study aligned with the ARDRA and ITS-PCR clusters, similar result were reported by Chenoll, Macián, and Aznar (2003) and Banwo et al. (2012). The phylogenetic relationship of LAB as it is based on the 16S rDNA gene sequence results showed clear differences between genera Lactobacillus, Pediococcus and Weissella. A phylogenetic tree based on the 16S rDNA sequence comparisons of LAB isolated from different Nigerian indigenous fermented foods are shown (Fig. 3).

The identification of LAB from traditional fermented foods using molecular techniques reduces labor, time and enhances rapid identification. These molecular techniques also complement the phenotypic method of LAB species identification. The use of two molecular markers; ARDRA and ITS-PCR analysis of 16S rRNA gene sequences identified LAB at genus level and gave good level of species differentiation. The profiles were reproducible and no variation in the restriction profiles of strains belonging to the same species were observed, it can be concluded that these techniques are fast, simple, non-expensive, and suitable alternative methods to the phenotypic procedures for the differentiation and characterization of LAB species which are commonly involved during the fermentation of the indigenous foods, and are also reliable when compared with other molecular techniques that may involve timeconsuming steps and more economical because they do not require numerous specific primers and expensive equipments.

\section{Conclusion}

From the study, the phenotypic, genotypic techniques and the sequencing of $16 \mathrm{~S}$ rDNA genes of the selected LAB representatives led to accurate species differentiation. The amplification of the16S-23S rDNA intergenic transcribed spacer (ITS) PCR and amplified ribosomal DNA restriction analysis technique have been shown to distinguish between the three predominant LAB species isolated from fermented foods. These techniques can be used either singly or in combination for greater reliability and rapid identification and differentiation of LAB species. These simple ARDRA and ITS-PCR techniques allow an economical, rapid, reliable and reproducible alternative as when compared with other techniques.

\section{Conflict of interest}

Authors declare that there are no conflicts of interest whatsoever. 


\section{Acknowledgment}

The authors are grateful to The World Academy of Sciences (TWAS) and the Department of Biotechnology (DBT), Ministry of Science and Technology, India for awarding the DBT-TWAS fellowship to Adesulu-Dahunsi Adekemi Titilayo in order to carry out this research.

\section{References}

Adewumi, G. A., Oguntoyinbo, F. A., Wahengbam, R., Singh, T. A., \& Jeyaram, K. (2014). Genome subtyping of autochthonous Bacillus species isolated from iru, a fermented Parkia biglobosa seed. Food Biotechnology, 28, 250-268.

Banwo, K., Abiodun, S. A., Tan, H., \& Tian, Y. (2012). Phenotypic and genotypic characterization of Lactic acid bacteria isolated from some Nigerian traditional fermented foods. Food Biotechnology, 26, 124-142.

Changnaud, P., Machinis, K., Coutte, L. A., Marecat, A., \& Merceiner, A. (2001). Rapid PCR-based procedure to identify lactic acid bacteria: Application to six common Lactobacillus species. Journal of Microbiological Methods, 44, 139-148.

Chenoll, E. M., Macián, C., \& Aznar, R. (2003). Identification of Carnobacterium, Lactobacillus, Leuconostoc and Pediococcus by rDNA-based techniques. Systematic and Applied Microbiology, 26, 546-556.

Cho, J. C., \& Tiedje, J. M. (2000). Biogeography and degree of endemicity of fluorescent Pseudomonas strains in soil. Applied Environmental Microbiology, 66, 5448-5456.

Collado, M. C., \& Hernandez, M. (2007). Identification and differentiation of Lactobacillus, Streptococcus and Bifidobacterium species in fermented milk products with bifidobacteria. Microbiology Research, 162, 86-92.

Collado, M. C., Moreno, Y., Cobo, J. M., \& Hernandez, M. (2006). Microbiological evaluation and molecular characterization of bifidobacteria strains in commercial fermented milks. European Food Research Technology, 12, 112-117.

Doulgeraki, A. I., Paramithiotis, S., Kagkli, D. M., \& Nychas, J. E. (2010). Lactic acid bacteria population dynamics during minced beef storage under aerobic or modified atmosphere packaging conditions. Food Microbiology, 27, 1028-1034.

Escalante, A., Wacher, C., \& Farres, A. (2001). Lactic acid bacteria diversity in the traditional Mexican fermented dough pozol as determined by 16S rDNA sequence analysis. International Journal of Food Microbiology, 64, 21-31.

Fusco, V., Quero, G. M., Stea, G., Morea, M., \& Visconti, A. (2011). Novel PCR-based Identification of Weissella confusa using an AFLP-derived marker. International Journal of Food Microbiology, 145, 437-443.

Gevers, D., Huys, G., \& Swings, J. (2001). Applicability of rep-PCR fingerprinting for identification of Lactobacillus species. FEMS Microbiology Letters, 205, 31-36.

Jensen, M. A., Webster, J. A., \& Strauss, N. (1993). Rapid identification of bacteria on the basis of polymerase chain reaction-amplified ribosomal DNA spacer polymorphisms. Applied Environmental Microbiology, 59, 945-952.

Jeyaram, K., Romi, W., Singh, T. A., Adewumi, G. A., Basanti, K., \& Oguntoyinbo, F. A. (2011). Distinct differentiation of closely related species of Bacillus subtilis group with industrial importance. Journal of Microbiological Methods, 87, 161-164.

Jeyaram, K., Romi, W., Singh, T. A., Devi, A. R., \& Devi, S. S. (2010). Bacterial species associated with traditional starter cultures used for fermented bamboo shoot production in Manipur state of India. International Journal of Food Microbiology, $143,1-8$.

Kostinek, M., Specht, I., Edward, V. A., Schillinger, U., Hertel, C., Holzapfel, W. H., et al. (2005). Diversity and technological properties of predominant lactic acid bacteria from fermented cassava used for the preparation of gari,a traditional African food. Systematic Applied Microbiology, 28, 527-540.

LeBlanc, J. G., Milani, C., deGiori, G. S., Sesma, F., vanSinderen, D., \& Ventura, M. (2013). Bacteria as vitamin suppliers to their host: A gut microbiota perspective. Current Opinion in Biotechnology, 24, 160-168.

Lechner, S., Mayr, R., Francis, K. P., Prub, B. M., Kaplan, T., WieBner-Gunkel, E., et al. (1998). Bacillus weihenstephanensis sp. nov. is a new psychotolerant of the $\mathrm{Ba}$ cillus group. International Journal of Systematic Evolution Microbiology, 48, 1373-1382.

Meroth, C. B., Walter, J., Hertel, C., Brandt, M. J., \& Hammes, W. P. (2003). Monitoring the bacterial population dynamics in sourdough fermentation processes by using PCR-denaturing gradient gel electrophoresis. Applied and Environmental Microbiology, 69, 475-482.

Mohammed, M., Abd El-Aziz, H., Omran, N., Anwar, S., Awad, S., \& El-Soda, M. (2009). Rep-PCR characterization and biochemical selection of lactic acid bacteria isolated from the Delta area of Egypt. International Journal of Food Microbiology, 128, 417-423.

Mohammed, S. U., Magray, D., Kumar, A., Rawat, A., \& Srivastavs, S. (2011). Identification of E. coli through analysis of 16S rRNA and 16S-23S rRNA internal transcribed spacer region sequences. Bioinformatics, 6, 370-371.

Moreira, J. L. S., Mota, R. M., Horta, M. F., Teixeria, S. M. R., Neumann, E., Nicoli, J. R., et al. (2005). Identification to the species level of Lactobacillus isolates in probiotic prospecting studies of human, animal or food origin by 16S-23S rRNA restriction profiling. BMC Microbiology, 5, 15. http://dx.doi.org/10.1186/14712180-5-15.

Munoz-Atienza, E Araújo, C, Del Campo, R, Hernandez, P, Herranza, C, \& Cintas, L. M. (2016). Safety assessment and molecular genetic profiling by pulsed-field gel electrophoresis (PFGE) and PCR-based techniques of Enterococcus faecium strains of food origin. LWT Food Science and Technology, 65, $357-362$.

Odunfa, S. A., \& Adeyele, S. (1985). Microbiological changes during the traditional production of ogi-baba West African fermented sorghum gruel. Journal of Cereal Science, 3, 173-180.

Oguntoyinbo, F. A., Huch, M., Cho, G. S., Schillinger, U., Holzapfel, W. H., Sanni, A. I., et al. (2010). Diversity of Bacillus species isolated from okpehe, a traditional fermented soup condiment from Nigeria. Journal of Food Protection, 73, $870-878$.

Oguntoyinbo, F. A., \& Narbad, A. (2012). Molecular characterization of lactic acid bacteria andin situ amylase expression during traditional fermentation of cereal foods. Food Microbiology, 31, 254-262.

Osorio, C. R., Collins, M. D., Romalde, J. L., \& Toranzo, A. E. (2005). Variation in 16S23S rRNA intergenic spacer regions in Photobacterium damselae: A mosaic-like structure. Applied Environmental Microbiology, 71, 636-645.

Sanni, A. I., Morlon-Guyot, J., \& Guyot, J. P. (2002). New efficient amylase-producing strains of Lactobacillus plantarum and L. fermentum isolated from different Nigerian traditional fermented foods. International Journal of Food Microbiology $72,53-62$.

Sneath, P. H., Mair, N. S., Sharpe, M. E., \& Holt, J. G. (2009). Bergey's manual of systemic bacteriology. Baltimore: kleins and Wilkins.

Stiles, M. E., \& Holzapfel, W. H. (1997). Review article: Lactic acid bacteria of foods and their current taxonomy. International Journal of Food Microbiology, 36, 1-29.

Tamang, J. P. (2010). Diversity of fermented foods. In J. P. Tamang, \& K. Kailasapathy (Eds.), Fermented foods and beverages of the World (pp. 41-84). New York: CRC Press, Taylor and Francis Group.

Tamang, J. P., Tamang, N., Thapa, S., Dewan, S., Tamang, B., Yonzan, H., et al. (2012). Microorganism and ethnic value of ethnic fermented foods and alcoholic beverages from North East, India. India Journal of Traditional Knowledge, 11, 7-25.

Tamura, K., Peterson, D., Peterson, N., Stecher, G., Nei, M., \& Kumar, S. (2011) MEGA5: Molecular evolutionary genetics analysis using maximum likelihood evolution distance and maximum parsimony methods. Molecular Biology and Evolution, 28, 2731-2739.

Teniola, O. D., Odunfa, S. A., \& Holzapfel, W. H. (2005). Selection, use and the influence of starter cultures in the nutrition and processing improvement of ogi. In I. D. Brouwer, A. S. Traoré, \& S. Trèche (Eds.), Proceedings of the 2nd international workshop: Food-based approaches for a healthy nutrition (pp. 697-708). Burkina Faso: Presses Universitaires de Ouagadougou.

Tilsala-Timisjarvi, A., \& Alatossava, T. (1997). Development of oligonucleotide primers from the 16S-23S rRNA intergenic sequences for identifying different dairy and probiotic bacteria by PCR. International Journal of Food Microbiology, 35, 49-56.

Versalovic, J., Schnedier, M., De Bruijn, F. J., \& Lupski, J. R. (1994). Genomic fingerprinting of bacteria using repetitive sequence-based polymerase chain reaction. Molecular Cell Biology, 5, 25-40.

Weisburg, W. G., Bams, S. M., Peletiar, D. A., \& Lane, D. J. (1991). 16S ribosomal DNA amplification for phylogenetic study. Journal of Bacteriology, 173, 697-703. 